\title{
Communication \\ Optimization of the Separation Parameters and Indicators of Separation Efficiency of Buckwheat Seeds
}

\author{
Stanisław Konopka *, Dariusz Jan Choszcz and Piotr Markowski \\ Department of Heavy Duty Machines and Research Methodology, University of Warmia and Mazury in Olsztyn, \\ 10-719 Olsztyn, Poland; dariusz.choszcz@uwm.edu.pl (D.J.C.); piotr.markowski@uwm.edu.pl (P.M.) \\ * Correspondence: stanislaw.konopka@uwm.edu.pl; Tel.: +48-089-523-36-07
}

Received: 2 October 2017; Accepted: 16 November 2017; Published: 20 November 2017

\begin{abstract}
The separation parameters and the indicators of separation efficiency for buckwheat seeds and impurities that are difficult to separate were optimized with the use of self-designed software based on genetic algorithms. The results of the calculations differed significantly from the suboptimal values determined in previous studies. The optimal values of the indicator of separation efficiency were higher; whereas the values of the indicator of buckwheat seed loss were significantly lower. The optimal working parameters for a seed separator in order to promote separation efficiency were determined.
\end{abstract}

Keywords: optimization; genetic algorithms; separation of buckwheat seeds

\section{Introduction}

In the classical approach, optimization is the process of determining the most effective (optimal) solution based on one or multiple criteria (indicators) [1].

Optimization decisions are made in daily life, and in the course of various planning, design and construction processes. Optimization is also an integral part of scientific research. However, the search for the optimal solution often relies on numerous, often contradictory, criteria. The above applies to the separation of seed mixtures and seed cleaning. Konopka [2] has reported the presence of impurities such as rye, wheat, oat and barley kernels, as well as segments of wild radish siliques in a separated mixture of buckwheat seeds. According to the author, these impurities often disqualify seeds from being used for sowing or food production (such as gluten-free foods). Choszcz [3] argued that low separation efficiency of cleavers seeds from rapeseeds grown for sowing can lower rapeseed yields by up to $40 \%$. These researchers have developed prototype devices for separating impurities from the main seed species. However, variations in evaluation criteria, such as the efficiency of impurity removal or the loss of seeds of the main species, have proved to be the main problem in the determination of the optimal working parameters in processing operations.

Analytical optimization methods contribute significantly to the objective selection of the most appropriate solutions. The best solution to a problem is determined by a problem's complexity and the choice of optimization method. Conventional optimization methods (gradient and gradient-free) are not effective for solving complex research problems. The above can be attributed to limited search space, multiple limiting criteria, continuity of the objective function, numerous local extrema and the unsuitability of conventional optimization methods for solving multiple-criterion problems [4]. According to a review of the literature, genetic (evolutionary) algorithms are one of the most popular optimization methods. Genetic algorithms are widely used to solve complex (nonlinear and multidimensional) problems in various fields of scientific research [5-10], because they eliminate many of the errors that are encountered in classical optimization methods. The main advantages of 
genetic algorithms include the multi-directional search for a solution space, resistance to local extrema, the exclusive use of objective functions in calculations (without the need for additional information, such as derivatives of the objective function), and their applicability for solving multi-modal and multiple-criterion problems [4].

The aim of this study was to determine the optimal separation parameters and indicators of separation efficiency for buckwheat seeds in a cylinder separator (with a rod structure), with the use of self-designed software and regression models (developed in a previous study) for describing the separation efficiency and loss of buckwheat seeds.

\section{Materials and Methods}

The separation of buckwheat seeds was analyzed in a separator with cylindrical units comprising rods with a circular cross-section. The separator was composed of two cylindrical units and a trough.

In the first cylinder, fine seeds are separated through the grooves between adjacent rods. Large seeds remaining in the cylinder are separated in the same manner as in a cylindrical trieur. The grooved cylinder combines the functions of a sieve and a cylindrical trieur [11].

The second cylinder does not feature grooves, and rods are positioned next to one another. This working unit operates on the same principle as a cylindrical trieur. The components of the seed mixture are separated with greater precision, and are guided to the trough.

The experimental test stand is presented in Figure 1 [2].

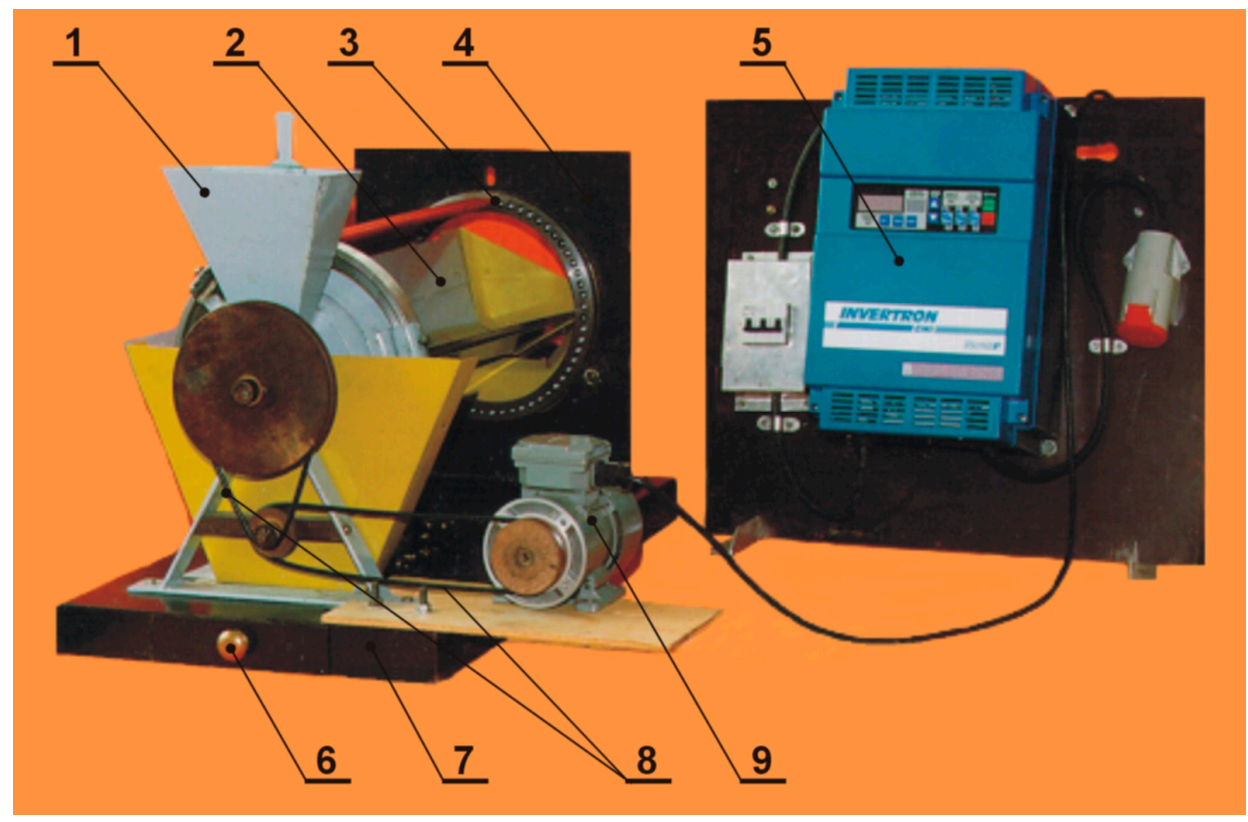

Figure 1. Experimental test stand: 1-seed hopper, 2-trough, 3-grooved cylinder, with several rods removed, 4-support, 5-frequency converter, 6-container for the separated fractions, 7-separator base, 8 -drive belt, 9 -electric motor.

The main component of the test stand is cylinder (3), which has a horizontal axis of rotation. Differently spaced rods with circular cross-sections form the lateral surface of the cylinder. The rods were made of pine wood, on account of its low volumetric mass density and ease of manufacture, and they were covered with PVC heat-shrink tubing. This type of tubing material was used based on the results of research indicating that PVC guarantees the greatest differences in the coefficients of external friction between buckwheat seeds and difficult-to-separate impurities [12]. The ends of the rods were placed in indentations in two rings to produce cylinders with a compact structure. The cylinders were mounted on supports (4), and a trough (2) was placed inside each cylinder. 
The trough could be moved along the device's longitudinal axis, and the position of the trough's edge could be changed. Power was transmitted to the cylinder by two drive belts (8). The motor's rotational speed was controlled by a frequency converter (5). The separator was equipped with a seed hopper (1) and a damper for controlling the flow of seeds into the cylinder. The container for the separated seed fractions (6) was assembled in the base (7) along the entire length of the cylinder. Similar containers (not shown in Figure 1) were mounted at the trough outlet [2,11].

The test stand had the following technical parameters:

- $\quad$ cylinder working length

- $\quad$ external diameter of cylinder rings

- $\quad$ distance between the edge of the trough and the cylinder

- $\quad$ inclination angle of the cylinder axis in the direction of the seed outlet

- motor output

- frequency converter

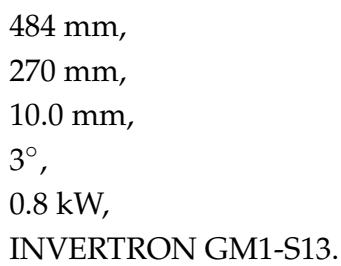

The test stand was composed of one grooved cylinder and five grooveless cylinders, which were mounted interchangeably during the experiment.

The grooved cylinder had the following technical parameters:

- $\quad$ diameter of grooves with PVC tubing

- cylinder's internal diameter

- $\quad$ number of bars forming the cylinder's lateral surface

- width of the separating groove

$$
\begin{aligned}
& 13.5 \mathrm{~mm}, \\
& 245 \mathrm{~mm}, \\
& 48, \\
& 3.1 \mathrm{~mm} .
\end{aligned}
$$

The dimensions (length and external diameter) of the grooveless cylinders were selected to ensure that they could be used as an interchangeable module in the separator with the grooved cylinder. The internal diameter of the cylinder rings and the internal pitch diameter of the rods were determined based on rod diameter. A certain amount of clearance (distance between the indentation contour and the external and internal diameter of the rings) had to be allowed for the indentations inside the rings where the rods were fixed. The clearance was set at $3 \mathrm{~mm}$ ( $1.5 \mathrm{~mm}$ on each side). The cylinders were made of rods with diameters of 15.0, 20.0, 25.0, 30.0 and $36.4 \mathrm{~mm}$ (Figure 2), and they differed in the number of grooves between the adjacent rods on the lateral surface.

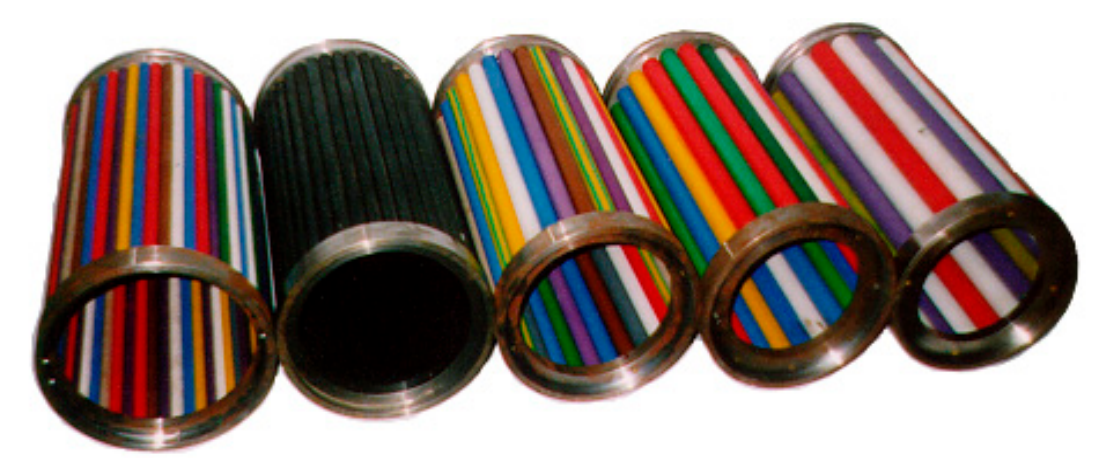

Figure 2. Grooveless cylinders composed of rods with increasing diameters [2].

The cylinders composed of rods with increasing diameters had 52, 38, 30, 24 and 20 grooves, respectively.

A study performed on a mixture of buckwheat seeds (purified material), kernels of four cereal species and wild radish siliques confirmed that devices of this type effectively separate buckwheat seeds for sowing and for the production of buckwheat groats. The separation process was analyzed at different operating parameters of the prototype separator. The study revealed that seed mixtures were most effectively separated in a two-stage process: I-in a cylinder composed of rods with a diameter of $13.5 \mathrm{~mm}$, separated by $3.1 \mathrm{~mm}$ grooves; and II-in a grooveless cylinder composed of rods with a diameter of $20 \mathrm{~mm}$ (final separation). Separation efficiency was determined by the angle of 
the working edge of the trough $\left(\alpha_{r}\right)$ and the cylinder's kinematic index $(k)$. The values of the above parameters were modified as follows:

- $\quad$ angle of the working edge of the trough $\left(\alpha_{r}\right)$-from 95 to $125^{\circ}$, in steps of $5^{\circ}$,

- $\quad$ cylinder's kinematic index $(k)$-from 0.15 to 0.55 , in steps of 0.1 .

The quality of the separation process was evaluated based on various criteria, in particular separation efficiency $\left(\varepsilon_{s}\right)$ and the loss of buckwheat seeds $(Z)$.

Stochastic mathematical models were developed to determine variations in separation efficiency based on the angle of the working edge of the trough $\left(\alpha_{r}\right)$ and the cylinder's kinematic index $(k)$. The results were used to determine suboptimal (extreme) values of the indicators of separation efficiency (including maximum $\varepsilon_{s}$ and minimum $Z$ ) and the corresponding values of parameters $\left(\alpha_{r}\right)$ and $(k)$. Attempts were made to determine whether buckwheat seeds were sorted at optimal operating parameters in the presented separator. The values of these parameters were modified in steps (not continuously), and the compared extreme values of separation quality indicators were observed for various combinations of these parameters.

The analyzed parameters were optimized with the use of self-designed software based on genetic algorithms. Genetic algorithms belong to a group of global optimization methods for solving nonlinear, multimodal and multiple-criterion problems. In comparison with other global optimization methods, genetic algorithms are less likely to converge towards local solutions rather than the global optima, and they facilitate search operations in large solution spaces $[4,13,14]$. The implementation of genetic algorithm procedures (selection of the analyzed population, evaluation of individuals, selection, crossing and mutation) and the user interface have been described in a previous study [15].

The self-designed software is composed of:

- a user interface written in Object Pascal in the Borland Delphi Enterprise programming environment $[16,17]$,

- a command interpreter of mathematical expressions based on the Reverse Polish Notation method [18],

- $\quad$ a module for 2D and 3D visualization of the solution space based on the OpenGL low-level graphics library,

- $\quad$ a computing module based on genetic algorithm data.

The above separation parameters and indicators of separation efficiency were optimized with the use of regression equations describing the correlations between the analyzed variables. The regression equations are presented in Table 1 [2].

Table 1. Regression equations for optimizing the indicators of separation efficiency $\left(\varepsilon_{s}, Z\right)$ and the working parameters $\left(\alpha_{r}, k\right)$ of the seed separator.

\begin{tabular}{lc}
\hline \multicolumn{1}{c}{ Working Surface in a Separator } & \multicolumn{1}{c}{ Regression Equation } \\
\hline Cylinder with grooves & $\bar{\varepsilon}_{s}=-4.542+0.102 \cdot \alpha_{r}-0.604 \cdot k-5.495 \cdot 10^{-4} \cdot \alpha_{r}^{2}+0.023 \cdot \alpha_{r} \cdot k-1.724 \cdot k^{2}$ \\
& $\bar{Z}=116.85-4.54 \cdot \alpha_{r}+436.82 \cdot k+0.04 \cdot \alpha_{r}{ }^{2}-4.53 \cdot k \cdot \alpha_{r}$ \\
\hline \multirow{2}{*}{ Grooveless cylinder } & $\bar{\varepsilon}_{s}=-1.614+0.080 \cdot \alpha_{r}-6.435 \cdot k-5.863 \cdot 10^{-4} \cdot \alpha_{r}^{2}+0.074 \cdot \alpha_{r} \cdot k-1.008 \cdot k^{2}$ \\
\hline
\end{tabular}

The optimization task was to determine the values of the working parameters $\left(\alpha_{r}, k\right)$ of the seed separator for which the objective function $(F)$ describing the indicators of separation efficiency $\left(\varepsilon_{s}, Z\right)$ fulfills the following equations:

$$
\begin{aligned}
& \mathcal{E}_{s}=F\left(\alpha_{r}, k\right) \rightarrow \text { maximum, } \\
& Z=F\left(\alpha_{r}, k\right) \rightarrow \text { minimum. }
\end{aligned}
$$

The calculations involved the following operations: 
- the appropriate forms of the objective function (stochastic models) were found,

- $\quad$ the search intervals (range of parameters) for the task were defined at $\alpha_{r}<95^{\circ} ; 125^{\circ}>$ and $k<0.15 ; 0.55>$,

- the direction of the optimization process (minimum or maximum) was selected,

- $\quad$ constraint functions (number of generations or time) were defined.

\section{Results and Discussion}

The optimized values of working parameters and indicators of the two-stage separation of buckwheat seeds in a separator with a grooved cylinder and a separator with a grooveless cylinder are presented in Figures 3-6. The optimized values are compared with suboptimal values in Table 2.

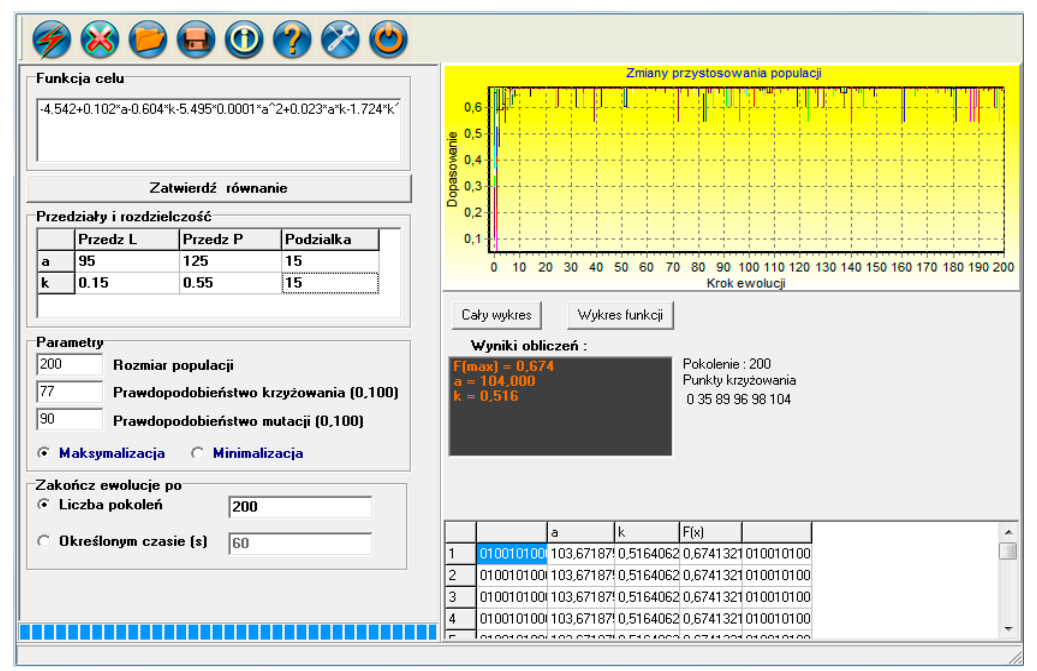

Figure 3. Graphic interface window with the optimized values of working parameters $\left(\alpha_{r}, k\right)$ and separation efficiency $\left(\varepsilon_{s}\right)$ of buckwheat seeds in a separator with a grooved cylinder.

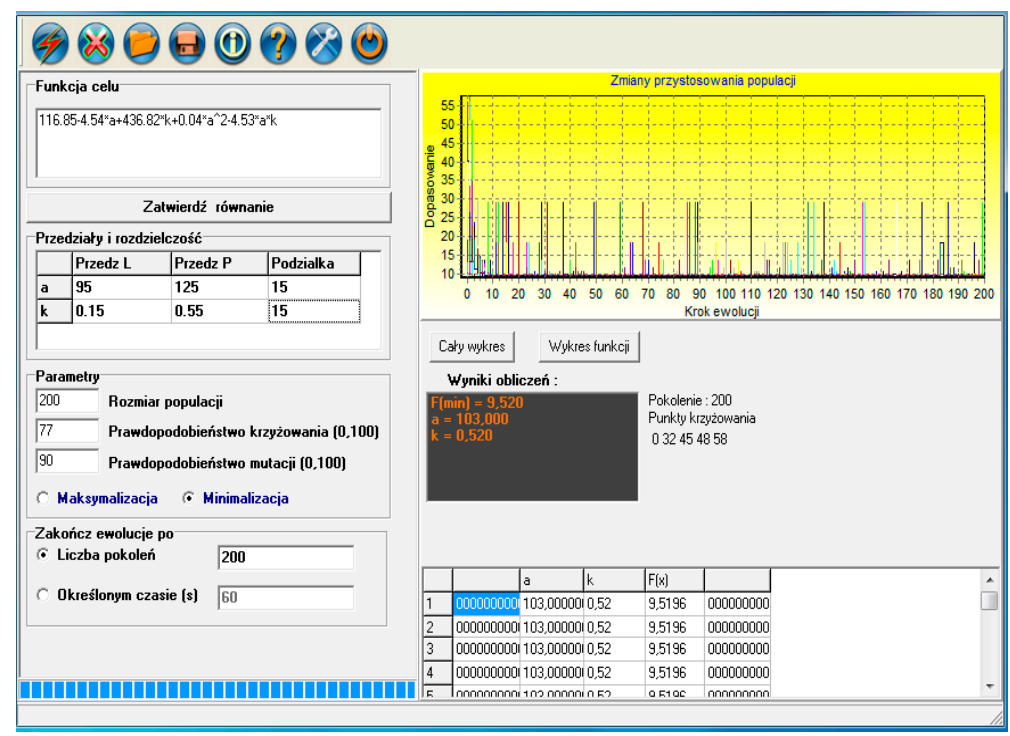

Figure 4. Graphic interface window with the optimized values of working parameters $\left(\alpha_{r}, k\right)$ and buckwheat seed loss $(Z)$ in a separator with a grooved cylinder. 


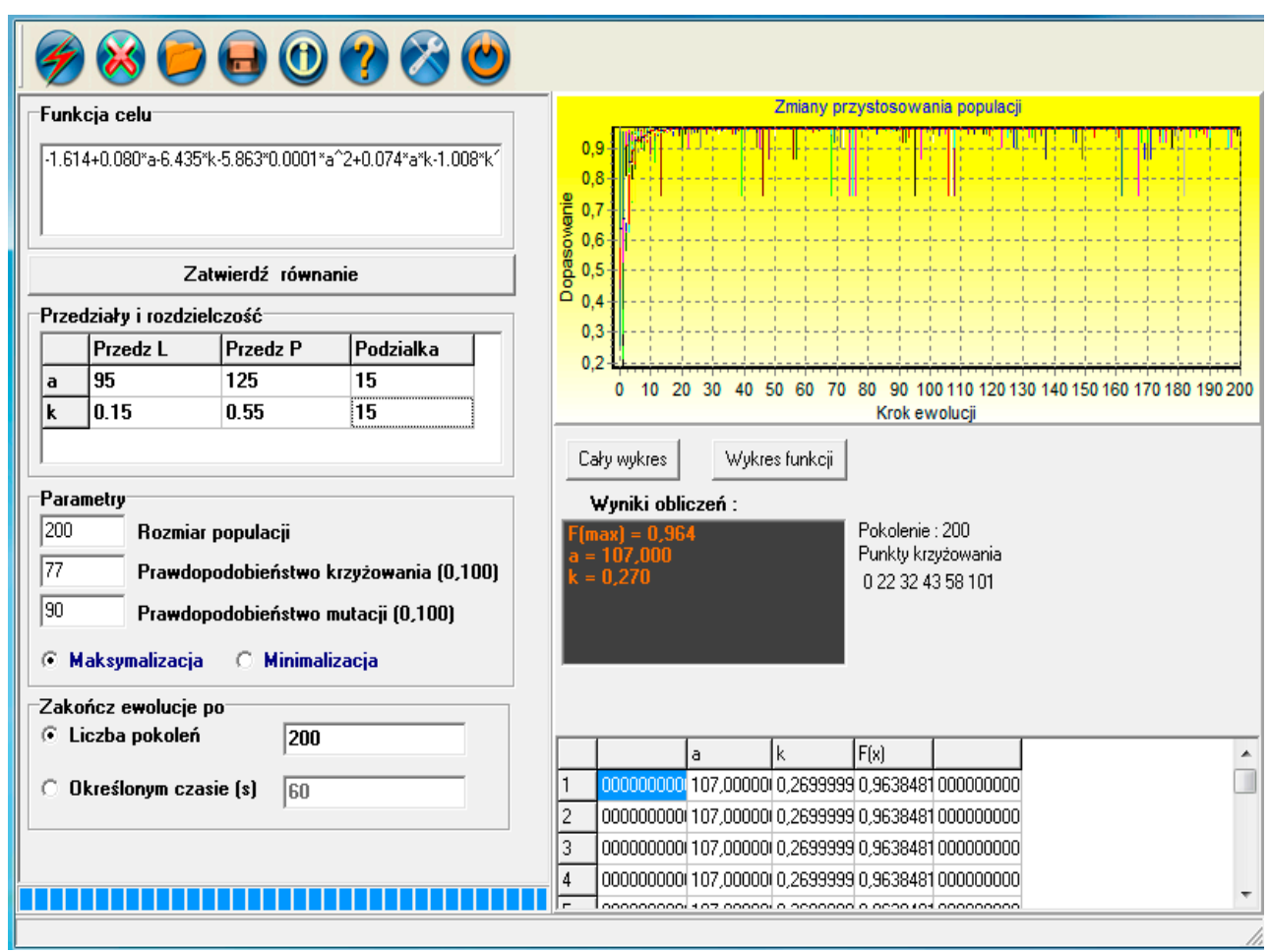

Figure 5. Graphic interface window with the optimized values of working parameters $\left(\alpha_{r}, k\right)$ and separation efficiency $\left(\varepsilon_{S}\right)$ of buckwheat seeds in a separator with a grooveless cylinder.

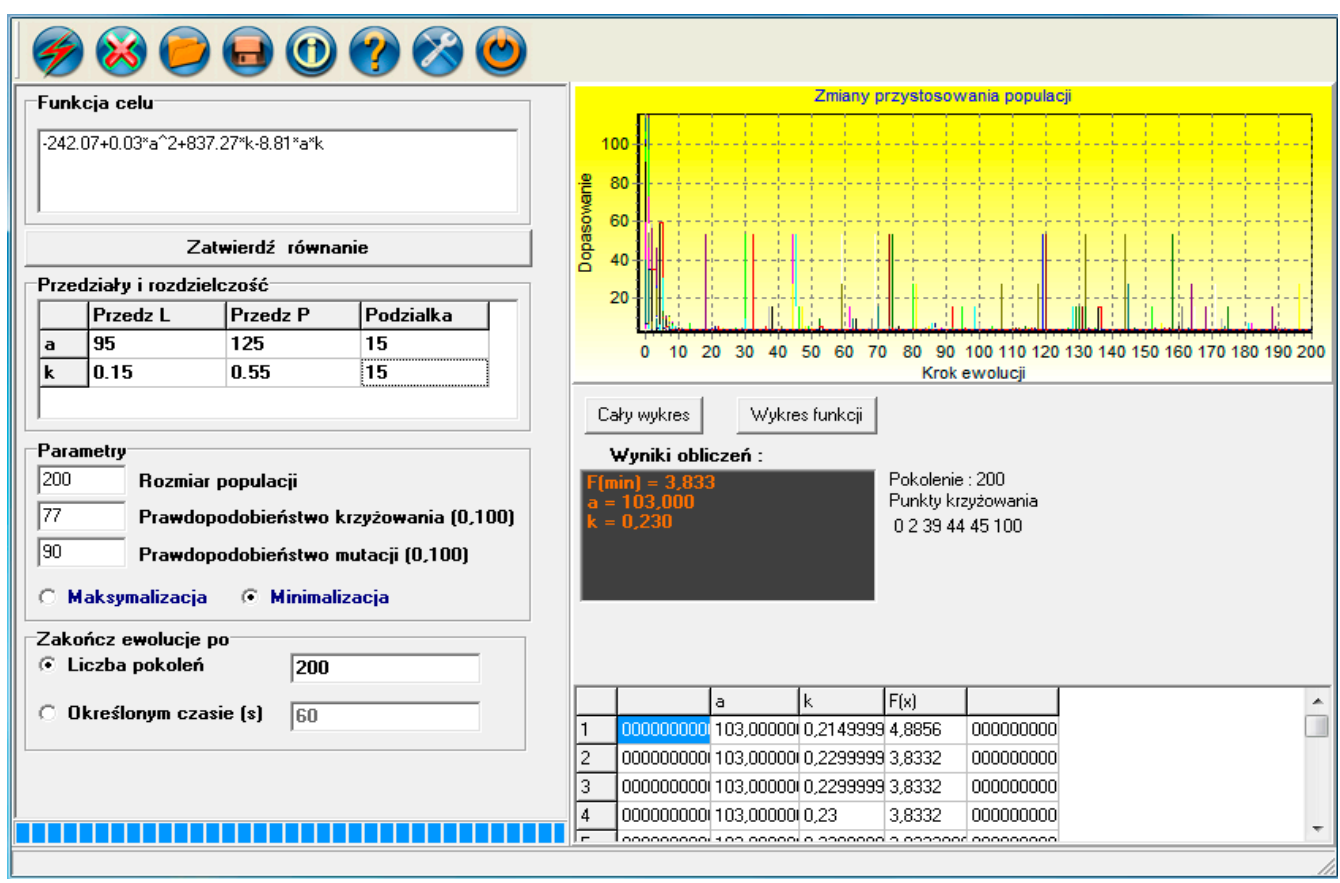

Figure 6. Graphic interface window with the optimized values of working parameters $\left(\alpha_{r}, k\right)$ and buckwheat seed loss $(Z)$ in a separator with a grooveless cylinder. 
Table 2. Comparison of the indicators of separation efficiency and working parameters in the process of separating buckwheat seeds in a cylindrical trieur.

\begin{tabular}{|c|c|c|c|c|c|c|}
\hline \multirow{3}{*}{ Separator } & \multicolumn{3}{|c|}{ Suboptimal Values [2] } & \multicolumn{3}{|c|}{ Values Optimized in Self-Designed Software } \\
\hline & \multirow{2}{*}{$\begin{array}{c}\text { Indicators of } \\
\text { Separation Efficiency }\end{array}$} & \multicolumn{2}{|c|}{ Working Parameters } & \multirow{2}{*}{$\begin{array}{c}\text { Indicators of } \\
\text { Separation Efficiency }\end{array}$} & \multicolumn{2}{|c|}{ Working Parameters } \\
\hline & & $k[-]$ & $\alpha_{r}\left[{ }^{\circ}\right]$ & & $k[-]$ & $\alpha_{r}\left[^{\circ}\right]$ \\
\hline \multirow{2}{*}{ with a grooved cylinder } & $\varepsilon_{S}=0.63$ & \multirow{2}{*}{0.35} & \multirow{2}{*}{110} & $\varepsilon_{s}=0.67$ & 0.52 & 104 \\
\hline & $Z=13.96$ & & & $Z=9.52$ & 0.52 & 103 \\
\hline \multirow{2}{*}{ with a grooveless cylinder } & $\varepsilon_{s}=0.92$ & \multirow{2}{*}{0.25} & \multirow{2}{*}{105} & $\varepsilon_{s}=0.96$ & 0.27 & 107 \\
\hline & $Z=6.41$ & & & $Z=3.83$ & 0.23 & 103 \\
\hline
\end{tabular}

A comparison of the indicators of separation efficiency $\left(\varepsilon_{s}, Z\right)$ of buckwheat seeds indicates that the separation process is more efficient when optimal values of the working parameters $\left(k, \alpha_{r}\right)$ are applied in practice. Higher separation efficiency $\left(\varepsilon_{s}\right)$ and lower seed loss $(Z)$ were noted in both variants of the separation process. The greatest differences between the values of the kinematic indicator $(k)$ were observed when the seed mixture was sorted in a separator with a grooved cylinder. The suboptimal value of the kinematic indicator $(k=0.35)$ differed significantly from its optimized value $(k=0.52)$, probably because the suboptimal value represents local extrema. Similar results were reported in [2], where the maximum values of partial indicators of separation efficiency (buckwheat seed gain and efficiency of impurity separation) were noted for different values of the kinematic indicator. Maximum seed gain was determined at $k=0.25$ and $k=0.35$, and the maximum efficiency of impurity separation at $k=0.15$ and $k=0.45$. The above values were also noted at different angles of the working edge of the trough $\left(\alpha_{r}\right)$.

\section{Conclusions}

The optimization of the parameters and indicators of separation efficiency of buckwheat seeds and impurities that are difficult to separate, performed with the use of self-designed software based on genetic algorithms, revealed that the proposed program supports the search for optimal solutions to multimodal and multiple-criteria problems. Results of numerical calculations of working parameters and indicators made it possible to determine the value of factors that increase the quality of the separation process. The optimal values of the indicator of separation efficiency were higher, whereas the values of the indicator of buckwheat seed loss were significantly lower.

Significant differences were observed between the values of the kinematic index, probably due to the presence of local extrema for this parameter. The genetic algorithm method supported the determination of indirect (optimal) values of working parameters despite the fact that the analyzed parameters were changed in steps in the experiment. For the proposed numerical method to be effective, the functions (equations) describing the correlations between the dependent variable and independent variables have to provide a good fit to the data.

Author Contributions: Stanisław Konopka and Dariusz Jan Choszcz conceived and carry out calculations; Stanisław Konopka and Piotr Markowski contributed to the literature study; Stanisław Konopka and Piotr Markowski analyzed the results of calculations; Stanisław Konopka and Piotr Markowski wrote the paper; Stanisław Konopka and Dariusz Jan Choszcz critically revised it.

Conflicts of Interest: The authors declare no conflict of interest.

\section{References}

1. Borzęcki, K. Leksykon Podręczny; Wydawnictwo Księgarnia Publisher: Olsztyn, Poland, 1994; pp. 1-242, ISBN 8390146703. (In Polish)

2. Konopka, S. Analiza procesu separacji nasion gryki przy wykorzystaniu prętowych powierzchni roboczych tryjerów. Inżynieria Rol. 2006, 8, 1-123. (In Polish)

3. Choszcz, D.J. Efektywność rozdzielania mieszaniny nasion rzepaku i przytulii czepnej w separatorze z taśma pętelkowa. Inżynieria Rol. 2009, 7, 1-106. (In Polish) 
4. Kisielińska, J. Elementy Teorii Optymalizacji Oraz Metody Rozwiąywania Zadań Optymalizacji Nieliniowej; SGGW: Warszawa, Poland, 2000; pp. 31-41. (In Polish)

5. Ahmed, S.G. Automatic generation of basis test paths using variable length genetic algorithm. Inf. Process. Lett. 2014, 114, 304-316.

6. Carrillo-Ureter, G.E.; Roberts, P.A.D.A.; Becerra, V.M. Genetic algorithm for optimal control of beer fermentation. In Proceedings of the IEEE International Symposium on Intelligent Control, Mexico City, Mexico, 5-7 September 2001; pp. 391-396.

7. Deb, K. Multi-Objective Optimization Using Evolutionary Algorithms; Wiley: Hoboken, NK, USA, 2001.

8. Harris, S.D.; Elliot, L.; Ingram, D.B.; Pourkashanian, M.; Wilson, C.W. The optimization of reaction rate parameters for chemical kinetic modeling of combustion using genetic algorithms. Comput. Methods Appl. Mech. Eng. 2000, 190, 1065-1090. [CrossRef]

9. Oduguwa, V.; Tiwari, A.; Roy, R. Evolutionary computing in manufacturing industry: An overview of recent applications. Appl. Soft Comput. 2005, 5, 281-299. [CrossRef]

10. Peňa-Reyes, C.A.; Sipper, M. Evolutionary computation in medicine: An overview. Artif. Intell. Med. 2000, 19, 1-23. [CrossRef]

11. Konopka, S. Urządzenie do Czyszczenia Mieszanin Nasiennych, Zwłaszcza Gryki. Patent PL 195961 B1, 30 November 2007. (In Polish)

12. Konopka, S. Studies on the Choice of Material Used for Making Bars of a Cylindrical Slotted Sieve. Tech. Sci. 2000, 3, 25-32. (In Polish)

13. Goldberg, D.E. Algorytmy Genetyczne I Ich Zastosowanie; Wydawnictwa Naukowo-Techniczne Publisher: Warszawa, Poland, 1998; pp. 1-303, ISBN 8320429706. (In Polish)

14. Arabas, J. Wykłady Z Algorytmów Ewolucyjnych; Wydawnictwa Naukowo-Techniczne Publisher: Warszawa, Poland, 2016; pp. 1-303, ISBN 8320429706. (In Polish)

15. Konopka, S.; Choszcz, D.; Wyrzykowski, P. Aplikacja metody algorytmów genetycznych do optymalizacji wskaźników jakości procesów rozdzielania mieszanin nasiennych. Zesz. Probl. Postęp. Nauk Rol. 2010, 546, 143-148. (In Polish)

16. Boduch, A. Delphi 7. Kompendium Programisty; Wydawnictwo Helion Publisher: Gliwice, Poland, 2003; pp. 1-686, ISBN 8373610871. (In Polish)

17. Grażyński, A.; Zarzycki, Z. Delphi 7. Błyskawiczne Tworzenie Aplikacji Dla Windows; Wydawnictwo Helion Publisher: Gliwice, Poland, 2003; ISBN 837361091X. (In Polish)

18. Cormen, T.H. Algorytmy bez tajemnic; Wydawnictwo Helion Publisher: Gliwice, Poland, 2013; pp. 1-224, ISBN 8373610871. (In Polish)

(C) 2017 by the authors. Licensee MDPI, Basel, Switzerland. This article is an open access article distributed under the terms and conditions of the Creative Commons Attribution (CC BY) license (http:// creativecommons.org/licenses/by/4.0/). 